Note: This is a pre-copy-editing, author-produced PDF of an article accepted for publication in Health and Social Care in the Community following peer review. The definitive publisher-authenticated version [Taggart L,

McLaughlin D, Quinn B and McFarlane C (2007) Listening to people with intellectual disabilities who misuse alcohol and drugs, Health and Social Care in the Community, 15(4), 360-368] is available online at

http://www3.interscience. wiley.com/journal/117968282/home

\title{
Listening to people with intellectual disabilities who misuse alcohol and drugs
}

\author{
Laurence Taggart, D. McLaughlin, B. Quinn and C. McFarlane \\ School of Nursing, University of Ulster, Coleraine, County Antrim, Northern Ireland
}

Published in Health and Social Care in the Community (2007) 15(4), 360-368
Published by Blackwell Science

\begin{abstract}
There is a dearth of research that has explored alcohol/drug use and misuse by people with intellectual disabilities. The aims of the present study were twofold: (1) to examine the insights of 10 people with intellectual disabilities into the reasons why they may misuse alcohol or drugs, and what impact this behaviour may have on them; and (2) to explore the services that they receive. Ten individuals with intellectual disabilities who were deemed to be misusing alcohol/drugs were purposively selected and interviewed. One overarching theme of the reasons for such misuse was labelled as 'self-medicating against life's negative experiences'. This was divided into two sub-themes: 'psychological trauma' and 'social distance from the community'. All the participants reported that their main source of support came from intellectual disability services, acting in both educational and liaison roles. Although seven of the individuals were referred to mainstream addiction services, they perceived this service as negative. In order to address these underlying problems, better access to a wider range of specialist services is required. Intellectual disability and mainstream addiction service providers also need to be more effective in the prevention and treatment of substance misuse by employing techniques such as motivational interviewing.
\end{abstract}

Keywords: Alcohol/drug misuse, intellectual disability, motivational interviewing, service user voice

\section{Introduction}

People with intellectual disabilities smoke and use alcohol, but at lower rates compared to the nondisabled population (Stavrakaki et al. 2002, Emerson \& Turnball 2005). Nevertheless, there is also growing evidence that some people with intellectual disabilities also misuse alcohol and illicit drugs (i.e. cannabis, solvents, ecstasy and amphetamines), and overuse prescribed medications (i.e. paracetamol, ibuprofen, benzodiazepines and codeine) (Sturmey et al. 2003, McGillicuddy 2006). In a recent study, Taggart et al. (2006) found that 67 people with intellectual disabilities residing in a region of the UK had a significant substance-related problem; this is an estimated $0.8 \%$ of the adult population with intellectual disabilities. However, this figure may be a lower estimate than the true prevalence rate, since the figure of $0.8 \%$ is only based upon those substance users who are known to services: therefore, it could be argued that prevalence rates may be higher.

Although the literature available on this topic is scant, what is available takes two forms. First, some whole or partial literature reviews of substance misuse in people with intellectual disabilities have been undertaken (Christian \& Poling 1997, Lance \& Longo 1997, Burgard et al. 2000, Degenhardt 2000, McGillicuddy 2006). Secondly, papers have been reported that have investigated specific substance misuse topics in this population, including: prevalence rates (Burgard et al. 2000, Emerson \& Turnball 2005, Taggart et al. 2006); risk factors (Robertson et al. 2000, Taggart et al. 2006); the impact of such misuse (Clarke \& Wilson 1999, Taggart et al. 2006); the development of specific treatment modalities (McMurran \& Lismore 1991, Campbell et al. 1994, Annand \& Rus 1998, Mendel \& Hopkins 2002); and service development issues (Tyas \& Rush 1993, Addictions Resource Agency for Commissioners 2002, Huxley et al. 2005). However, there is no evidence of published research that has directly sought to seek 
the insights of service users into the reasons why they use substances, how it has impacted upon their well-being and how they would like services to be developed.

Given the growing recognition and value of incorporating the individuals' voice into planning, developing and commissioning future services for people with intellectual disabilities, it is important that such marginalised groups are represented (Chappell 2000). It has been strongly argued that obtaining the insights of people with intellectual disabilities has the potential to emancipate and empower this client group (Atkinson 2005). Obtaining information on substance misuse by individuals with intellectual disabilities offers the potential to help both intellectual disability and mainstream addiction service providers to identify the specific support systems that are needed to meet the needs of this client group: hence, services will be service user-led. The aims of the present study were twofold: (1) to examine the insights of this population into the reasons for and impact of their substance misuse; and (2) to explore the services that this client group has received.

\section{Subjects and methods}

Qualitative methodology was employed to further engage with people with intellectual disabilities: such methods have often successfully used focus groups and semistructured interviews (Barr et al. 2003, McConkey et al. 2004, Atkinson 2005). A qualitative approach was most suitable to study the area of substance misuse because this is a sensitive area and individuals are not always forthcoming in reporting their use of such substances, and in addition, there is little existing knowledge of this area. The present study used a series of semistructured one-to-one interviews.

\section{Participants and settings}

From an earlier study undertaken by Taggart et al. (2006) across a region of the UK, 54 community informants (i.e. social workers and community nurses) completed a questionnaire about 67 individuals who were identified as having a co-morbidity involving an intellectual disability and a substance disorder by using DSM-IV criteria (American Psychiatric Association 1994). Of the 67 potential participants identified, only 10 could be recruited to participate in a one-to-one semi-structured interview. The majority of the community informants reported that their clients were not 'willing' to be interviewed about their substance misuse habits since they did not perceive themselves as having any 'problems/issues' with alcohol and/or drugs.

\section{Procedure}

Written information explaining the purpose and nature of the project was forwarded to the community informants. Similarly, written information regarding the nature of the project, the procedure (i.e. the audio-taping of the interviews), consent and reassuring confidentiality was also provided for clients in a more user-friendly format.

When a suitable time was agreed, two members of the research team met each participant. In accordance with the subjects' wishes, eight interviews were conducted within a private room in a health centre or day centre, and two interviews took place within the person's own home. Eight of the individuals requested the presence of their social worker or community nurse during the interview, whereas another asked that his mother sit in on the interview, and yet another did not wish to have anyone else present other than the two research staff.

Using a user-friendly individual information sheet and consent form, the lead researcher (L.T.) read out an introductory statement regarding the purpose and nature of the study. In terms of the recording of the interviews, eight individuals gave their permission for the interviews to be audio-taped while two others refused, although they did give their approval for the research assistant to take notes. All the individuals were informed about the confidentiality of the audiotapes/ notes and that no identifiable information would be shared. All the individuals provided written consent to their participation in the study.

\section{Interview format}

Based upon a detailed literature review, the interviews followed a flexible structure. The subjects were initially asked about the type of substance that they used and the frequency of their consumption. Other questions focussed upon the individuals' insights into the cause of their hazardous patterns of substance 
use, and any worries they had about the substance(s) effects upon their body, mind and their friends. Questions were also asked about the services that the participants had received to help/support them with their substance-related behaviours and the reasons for their substance misuse. The interview schedule also included a number of probing questions that would aid the individual to expand upon their answers, thereby providing further clarity and explanation. Two pilot/field trial interviews were conducted and no difficulties were identified with the interview schedule. Each interview lasted approximately 40 to $50 \mathrm{~min}$.

\section{Ethical considerations}

The Health and Personal Social Services Research Ethics Committee (Lisburn, N. Ireland) granted ethical approval for this project. Informed consent was sought from each individual in two ways. First, each community informant spoke with the individual about the project and provided them with a written copy of the user-friendly 'individual information sheet'. Secondly, the lead researcher (L.T.) reiterated the purpose of the study and the nature of the interview procedure, and this also included emphasising the confidentiality of what would be said. In addition to agreeing to take part in the

study, all participants were informed that they could withdraw at any time should they find the interview in any way uncomfortable, but none selected to do so.

\section{Data analysis}

In order to ensure the truthfulness and consistency of the qualitative data reported within the present study, a range of a priori methods were employed (Slevin \& Sines 2000, Parahoo 2006). First, recording the interviews and transcribing the tapes verbatim assured consistent and accurate accounts of the individual's knowledge and experiences. Secondly, all available community informants were asked to verify the truthfulness of their client's reports and any paradoxical statements reported were subsequently examined. Thirdly, the data were subjected to a thematic content analysis using Burnard's (1991) framework. Key points made by the individuals were identified and assigned a colour code using the NVivo computer program (QSR International Pty, Doncaster, Victoria, Australia); similar codes were gathered together into themes and sub-themes. Fourthly, to authenticate these key themes and subthemes, as identified by the first author (L.T.), two members of the research team (D. McL. + B.Q.) was asked to examine all the transcripts: disagreements were discussed and consensus sought. Lastly, an independent expert in the field of addictions was consulted and asked to examine exemplars of the transcripts, and the themes and sub-themes that were subsequently identified, in light of the mainstream addiction literature. The systematic approach employed within the present study further increases the truthfulness and consistency of the qualitative findings, and thereby, enhances the transfer value of the findings.

\section{Results \\ Individuals}

Ten individuals took part in the semi-structured interviews (seven females and three males). The ages of the participants ranged from 28 to 52 years. Nine of the individuals were reported by the community informants to have a borderline/mild intellectual disability and one person had a moderate intellectual disability. With regard to the individuals' living arrangements, five of the users lived independently within their own flat/house, two lived with a family member, two resided within a supported living scheme and one user lived within a residential facility. The community informants reported that four participants had a psychiatric diagnosis of an affective disorder, and three were suspected of having a mental health problem but had not been diagnosed as such. Some of the reasons cited for this suspected diagnoses included 'a history of sexual abuse by her father', 'history of self-harm', 'suicidal ideation', 'cutting wrists', 'overdosing', 'insomnia', 'loss of appetite', 'apathy' and 'obsessional behaviour'. Whether these problems contribute to substance misuse is unclear and requires further examination.

In terms of the substances used, seven individuals had reported using alcohol only. Three women reported using a combination of alcohol, illicit drugs (e.g. cannabis and ecstasy) and prescribed medications (e.g. paracetamol, codeine and diazepam). All the individuals reported that they had long histories of alcohol misuse, i.e. over 5 years, and the community informants supported these findings. Nevertheless, within the past 12 months, two people had stopped abusing substances because of 
specific life circumstances (i.e. 'a miscarriage' and 'physical health deterioration'), and another six reported that they had reduced their patterns of hazardous substance usage and were now using alcohol in moderation. However, yet another two participants continued to engage in harmful patterns of binge drinking and other substance misuses.

\section{Reasons for misusing substances}

The overarching theme that emerged from the transcripts was labelled as 'self-medicating against life's negative experiences'. This could be divided into two emotive sub-themes: (1) 'psychological trauma'; and (2) 'social distance from their community'. Both these sub-themes were closely related. Table 1 details a number of narrative accounts of reasons for abusing substances.

\section{Psychological trauma}

Within this theme, one man spoke of experiencing the multiple deaths of close family members, including losing his brother as the result of a 'being murdered'. Two females reiterated accounts of loss through the death of their partners, with one woman finding her partner dead in the bed beside her. Other female participants told disturbing accounts of how they have suffered long-term physical, emotional and financial abuse at the hands of the partners whom they had lived with previously. One woman reported that she had been 'sexually abused by her father'. Another told a harrowing story of how she was raped on two separate occasions when intoxicated.

An additional recurring theme that developed from the interviews with a number of the individuals was a deterioration in their mental health when drinking. Some individuals hazardously misused substances when 'feeling down', whereas others suffered from bouts of depression after binge drinking. Three of the women spoke of their attempts to self-harm when drunk. One female participant also spoke poignantly of how she tried to take an overdose and then attempted to hang herself, as well as cutting her wrists. These individuals reiterated how these painful memories of loss, sadness, despair, confusion and hurt were some of their reasons for this long-term use/misuse of alcohol and/or other substances.

Table 1 Reasons for abusing substances: psychological trauma and social distance from the community

\begin{tabular}{lll}
\hline Participant & Sex & Reason \\
\hline P9 & Male & $\begin{array}{l}\text { 'Well, after my brother died -he was shot dead, you know - and then my sister died, and } \\
\text { my mother died as well. It plays on your mind, and I drink to kill the pain. When you have } \\
\text { drink in you, you're in a different world but it [the pain] is still there the next day.' }\end{array}$ \\
P4 & $\begin{array}{l}\text { Female } \\
\text { P2 }\end{array}$ & $\begin{array}{l}\text { 'It made me forget the past and everything that happened about the rapes.' } \\
\text { 'He [partner] made me buy the drink, then we sat and drank together. If I didn't get the } \\
\text { frink for him, he would put me against the wall many times, hitting me.' }\end{array}$ \\
P6 & Male & $\begin{array}{l}\text { 'I gave them [her non-disabled drinking peers] drink, food or that, but I was buying my } \\
\text { friendship. See, when you have money, they want you, and now that I don't have any } \\
\text { money, they don't want you no more. They just say to me, "You have to give me stuff." } \\
\text { 'I kept going to the pub for company. Even though I sit at the bar and get drunk by myself, } \\
\text { at least it gets me out of the house.' } \\
\text { 'After my partner had died, I became lonely and all that ... There was no one living in the } \\
\text { flat with me ...I just feel lonely and all that: I have nothing to do but watch TV' }\end{array}$ \\
P5 & Female & Female
\end{tabular}

\section{Social distance from their community}

Many of the informants spoke of their lack of companionship, of having no friends, whether non-disabled or disabled, and the loneliness of living by oneself. Others recounted stories of being exploited by their 'drinking peers', people who they drank with on the streets, in the pubs and in their own homes. These 'so-called friends' exploited one person's goodwill to use their flat, their money, their food and also her personal possessions. Another man described his years of being bullied at school because of his cognitive deficits and being different.

Overall, a disturbing trend that could be heard throughout many of the interviews was that of isolation and loneliness. A number of individuals also reported drinking either with their partner or alone in their own home. Some drank in bars alone in an attempt to meet/talk to somebody. Others reported that they drank with (nondisabled) people they believed were their friends in bars, clubs and on the streets, but in 
hindsight, these so-called friends were actually exploiting the individuals for their own gain, either for money to buy drink and/ or food, or in some cases, sexually. On the other hand, some participants reported that they were aware of this particular scenario, but were content to have some company despite the potential risks that could occur.

\section{Life impacts of alcohol misuse}

Information was sought from the participants about their insights into how these substances had affected them. Four sub-themes emerged from the transcripts. These focused on the physiological effects, the effects upon the person's mind and the financial implications (including losing one's own independence and home). Lastly, the individuals also spoke about how their relationships with their families, partners and peers had deteriorated, often resulting in verbal and physical confrontations when drinking.

The quotations in Table 2 prove that all the individuals had some insight into the impact of drinking excessively on their physical health. One woman reported that she had twice been taken to an acute medical hospital within a short period of time as a result of the effects of excessive drinking. Consequently, she has controlled her drinking patterns because she is afraid of further complications regarding her health. The majority of the individuals also spoke about the effects of the hazardous use of alcohol upon their mental health. Some reported periods when they could not remember the previous night's activities. Another disturbing area that emerged was the number of women who reiterated accounts of suicidal ideation and actual self-harm.

For a number of participants, the consequences of prolonged hazardous drinking accompanied with numerous alcohol/drug-related behaviours have resulted in conflicts with those with whom they live. Two individuals who had lived in their own accommodation had subsequently lost their independence because they had to return to live with their family or be placed within a supported living scheme. The majority of participants also reported frequent arguments with family members, partners and peers. Some reported that they had become physically violent towards a family member or their partner. Conversely, their family member or partner had also become physically violent towards them after various arguments when both parties were intoxicated. Drink-related behaviours resulted in others getting into trouble with the police. Furthermore, all of the individuals reported that they were conscious of the financial implications of their spending, finding there was little food in the house.

Table 2 Effects of the substance misuse

\begin{tabular}{|c|c|c|}
\hline Participant & Sex & Reason \\
\hline P5 & Female* $^{*}$ & $\begin{array}{l}\text { 'When I drink, my blood sugars seem to drop ... I also worry about my fits ... as sometimes } \\
\text { I forget to take } \\
\text { my tablets.' }\end{array}$ \\
\hline P6 & Female† & $\begin{array}{l}\text { 'I get such hangovers and forget to take my medication ... I fell down the stairs and cut my } \\
\text { head open twice.' }\end{array}$ \\
\hline P2 & Female & $\begin{array}{l}\text { 'Because I lost my baby, miscarried when I was drinking previously ... so when I found out } \\
\text { I was pregnant again, I stopped drinking immediately.' }\end{array}$ \\
\hline P6 & Female & $\begin{array}{l}\text { 'Sometimes I don't know what I am doing. I have slashed my wrists before when drinking } \\
\text { heavily.' }\end{array}$ \\
\hline $\mathrm{P} 1$ & Female & 'Yes, a bit, because I was slicing my wrists and took an overdose.' \\
\hline P10 & Female & 'I attempted suicide twice, tried using a razor-blade and a rope.' \\
\hline $\mathrm{P} 1$ & Female & $\begin{array}{l}\text { 'When my mum drinks Smirnoff, we always argue. Like about } 3 \text { weeks ago, my mum was } \\
\text { drinking and we got into a massive argument and she hit me, so I hit her back, and I was } \\
\text { so scared when she was hitting me that I hid under the kitchen table from her.' }\end{array}$ \\
\hline P7 & Female & $\begin{array}{l}\text { 'When I was drunk, I would shout at my friends [peers living in supported living scheme] ... } \\
\text { You could have heard me from the corridor.' }\end{array}$ \\
\hline $\mathrm{P} 1$ & Female & $\begin{array}{l}\text { 'I was arrested for assaulting two police officers while drunk, but was released on bail into } \\
\text { the care of my sister when it was explained that I had a learning disability.' }\end{array}$ \\
\hline
\end{tabular}




\section{Supports/services}

When the participants were asked about the support systems and services that they had received to manage their drinking patterns, three main health groups were identified.

\section{Intellectual disability services}

All of the individuals reported being in contact with members of the community intellectual disability team (i.e. social worker and/or community nurse). Many participants described the positive educational role that these personnel adopted regarding controlling the individuals' drinking habits and the dangers of excessive drinking. Another function that such informants provided was a liaison role with the individuals' families, day centres/employers, general practitioners (GPs), acute and intellectual disability hospitals, and also mainstream addiction services, where appropriate. Table 3 details a number of narrative accounts of the services that this client group received.

Two individuals indicated that they were admitted into a hospital for people with intellectual disabilities. One woman reported that she was admitted for a 6-week period. This removal from her home and life circumstances, accompanied by advice from the hospital staff, resulted in her reducing her harmful levels of alcohol consumption. However, many of the individuals reported that these community personnel, although extremely beneficial in terms of advice and practical help, could do little to persuade them to halt their hazardous drinking regimes.

\section{Mainstream addiction services}

Seven participants reported that they had been referred to mainstream addiction services by their social worker and/or nurse. Of these individuals, the majority indicated that they attended group sessions based upon the provision of educational leaflets, videos and group sharing. The majority reported that the group sharing was ineffective, and more worryingly, they felt perturbed at sharing their personal life stories in settings with other patients. Many of these sessions ended abruptly with the person refusing to go back to the mainstream addiction services.

Nevertheless, two individuals positively described their interactions with these services: meeting regularly with an addiction counsellor and working together on a one-to-one basis. However, for both individuals to be seen by the addiction counsellor, each person had to be, in their words, 'off the drink'.

Table 3 Service provision

\begin{tabular}{|c|c|c|}
\hline Participant & Sex & Reason \\
\hline \multicolumn{3}{|c|}{ Intellectual disability services } \\
\hline P1 & Female & $\begin{array}{l}\text { 'X [social worker] contacts me at least twice a week by either telephone calls or visits; she } \\
\text { helps me stick to my goals and staying off the drink.' }\end{array}$ \\
\hline P7 & Female & $\begin{array}{l}\text { 'We used a wee diagram looking at the different parts of the body and how it is affected you } \\
\text {... This was helpful.' }\end{array}$ \\
\hline \multicolumn{3}{|c|}{ Mainstream addiction services } \\
\hline P6 & Female & $\begin{array}{l}\text { '... I don't like sitting in meetings and just tell them [mainstream addiction staff] because I } \\
\text { would be too scared ... I don't liked being asked personal questions in front of all them [other } \\
\text { patients].' }\end{array}$ \\
\hline P1 & Female & $\begin{array}{l}\text { 'I went to a dry-out ward, but I only stayed for about } 2 \text { weeks and lay in bed crying to go } \\
\text { home. I was scared because people were sitting in a circle talking about their lives that } \\
\text { scared me ... I felt forced to talk about my family history ... I didn't want to do that.' }\end{array}$ \\
\hline P7 & Female & $\begin{array}{l}\text { 'I don't like going into all that again. I don't mind talking in confidence with one person, but } \\
\text { when there are a lot of people, I won't talk.' }\end{array}$ \\
\hline P8 & Male & $\begin{array}{l}\text { 'I went to a counsellor from the addiction services ... It was grand. I talked to him openly, } \\
\text { and it was good, you know' }\end{array}$ \\
\hline
\end{tabular}

\section{Primary care services}

All the participants reported speaking to their GPs at some stage about their substance misuse and related problems. The individuals indicated that the GPs attempted to offer little more than advice, providing some individuals with information leaflets, and encouraging them to diminish their drinking patterns totally. Others were also prescribed antidepressants to manage their mental health. 


\section{Utilisation of specialist support networks/groups}

More distressingly, when the individuals were asked whether they were referred to or attended any specific support networks/groups to address their negative life experiences (i.e. bereavement and other losses, mental health problems, domestic violence, and sexual abuse), all of them reported that they had not been offered/ received the opportunity to attend any specific supports. One woman sadly summarised the futility and helplessness of this situation, which is one that many people with intellectual disabilities have to face:

Nobody wanted to help me unless I was lying half dead or something ... My mummy tried to get me help with my depression and the drink ... Nobody did anything about it. (P10, female)

\section{Service developments}

When the individuals were asked about how future services should be developed to meet the needs of other people like themselves, a number of themes were identified. Overall, the individuals reported that they would prefer discussing their substance-related problems and life circumstances on a one-to-one basis rather than in the intimidating group sessions that some individuals had experienced in the past. It was also suggested that the availability of a wider network of friendships in which the person could engage in various recreational/ diversional pursuits would widen the persons' social support network. Some people also identified the provision of more formative structures focussing upon employment and education during the day. Others also suggested greater family support and involvement in the persons' treatment package.

Another theme that clearly emerged from the transcripts concerned the person's motivation to lessen or discontinue their hazardous patterns of substance use (i.e. 'wanting to give up yourself' or 'taking control of yourself and of your own life'). This can be summarised by the following quote:

I wouldn't tell them [other people with intellectual disabilities] to stop. I would tell them it doesn't solve your problems - they are still there the next day. (P9, male, lost his home after substance-related behaviours, but is now a moderate drinker)

\section{Discussion}

The present study has shown that the hazardous use of substances by these 10 people with intellectual disabilities was accompanied by a range of underlying issues, such as: mental health problems, selfharm, domestic violence, bereavements, and physical and/or sexual abuse. There is a need to engage in discussions around such emotive issues. However, in conducting research with this marginalised population, sensitivity and meticulous care needs to be taken in order to protect the individuals involved (Atkinson 2005).

It is vital that the individuals are fully informed about the nature of the interviews. Appropriate userfriendly participation information sheets should be provided, clear guidance should be given about informed consent, a choice of where the interviews take place should be available, interviews should be flexible and use appropriate language, and participants should be given the opportunity to have their community informant present or not. In many cases, the presence of the social worker or community nurse did not seem to restrict the content of the interview as one might have expected. On the contrary, the community informant prompted the individual to answer more fully and clarified some of the individuals' answers. Moreover, given the poignant responses of many of the individuals that highlighted why they used/misused substances and the impact that this has had upon their well-being, this support from the informants also offered the individuals further reassurance, making them feel comfortable when disclosing parts of their life stories, albeit ones already known to these staff.

The present study has shown that these 10 people with intellectual disabilities use alcohol, and other substances, for the same reasons as their non-disabled peers (Banerjee et al. 2002), although little research has been published on this topic. This includes both its positive (i.e. relaxation and enhancing social relationships with others) and negative (i.e. in relation to bereavement, abuse, depression and loneliness) reinforcing properties. Moreover, a number of the people interviewed drank as a means of 
fitting in and being accepted by their nondisabled peers and to avoid loneliness. Furthermore, the present study found that many of the people interviewed reported having limited work and recreational opportunities, possibly leading them to use a range of substances as a means to avoid boredom and integrate with others.

Therefore, although the data are based upon a limited sample, it can be argued that the members of this population have a number of related reasons for their long-term hazardous substance use patterns. This multiple diagnoses thereby extends Barnhill's (2000) label of a 'triple diagnosis' (i.e. an intellectual disability, a mental health problem and a substance-related disorder), further accentuating the complex issues that need to be managed by front-line care staff, many of whom have not had specific training in this area, even though it is one that needs further scrutiny.

Likewise, none of the individuals reported being referred onto other specialist services to address these negative life experiences. In order that the needs of these people are fully met and not superficially addressed, service providers may need to consider developing more holistic multimodal treatment packages of care that involve an integrative approach between intellectual disability services, mainstream addiction teams and other healthcare specialists. Moreover, services need to address these issues proactively rather than managing the consequences of such negative life experiences. Although some of the participants in the present study were able to access mainstream addiction services, it must be acknowledged that current addiction teams may already be overstretched in providing services to the non-disabled population, and therefore, may be reluctant to offer a service to a 'difficult' client group when the teams have few resources and no available models of good practice for working with this doubly disadvantaged population.

All of the study participants were able to report many of the negative effects of their hazardous drinking and substance use upon their physical, mental and social health. These risks need to be attentively observed, but this is mainly a population who live independent lives, with some people remaining unknown to services until the problems are deep-seated (Taggart et al. 2006). This is a scenario that also has to be balanced regarding each person's rights to independence and inclusion that are being strongly advocated in current legislation across the UK; for example, Valuing People (Department of Health 2001) in England and Wales, The Same as You? (2001) in Scotland and Equal Lives (Review of Mental Health and Learning Disability (Northern Ireland) 2005) in Northern Ireland. Nevertheless, there is little emphasis being placed upon promoting safe drinking patterns, policies of abstinence/moderation, and developing an integrated approach between intellectual disability and addiction services for this population.

The present study was not without its difficulties. Despite having access to 67 individuals, only 10 participated. The research team contacted each of the community informants who had previously completed a demographic questionnaire in an earlier study (Taggart et al. 2006). However, the majority of the informants highlighted that over 50 of the clients were not willing to engage in the interviews because they did not perceive themselves as having a substance-related problem, and therefore, were possibly in denial and not motivated to engage with services or make any change to their current behaviours (Rivinius 1988). However, although the 10 individuals may not be representative of the cohort who refused to participate in the present study, this sample does represent a range of people with intellectual disabilities who have previously misused substances, but are now moderate drinkers, although two participants currently report abusing substances. Therefore, as a result of their greater insight into their substance-related behaviours and a determined willingness to change their behaviours, these individuals fully engaged with the researchers. If things had been otherwise, the voice of this population could have remained hidden.

The importance of motivation for change in the prevention and treatment of alcohol and drug misuse is widely recognised in the mainstream addiction literature because it is believed that treatment failure is also partly caused by a lack of personal motivation. Miller $(1983,1988)$ introduced an approach called 'motivational interviewing', which de-emphasises labelling, encourages individual responsibility, and increases the person's dissonance between their goal and present behaviour. Recently, both mainstream mental health and addiction services have been effectively using motivational interviewing techniques as one of the most appropriate ways to motivate clients, moving them from a pre-contemplation to a 
contemplation mindset, and then on to action and maintenance (Prochaska \& Di Clemente 1986). While the present study did not investigate the use of motivational interviewing with individuals who have an intellectual disability and are abusing substances, the approach may be beneficial when working with this client group. Although no studies have examined the use or efficacy of motivational interviewing for people with intellectual disabilities, a small number of innovative practitioners are employing these techniques with promising results (Mendel \& Hopkins 2002).

\section{Conclusion}

The present study found that, like their non-disabled peers, these individuals with intellectual disabilities use/misuse a range of substances to 'self-medicate against life's negative experiences'. These life stories, involving harrowing accounts of bereavement, mental health problems, self-harm, domestic violence, physical and sexual abuse, and loneliness and isolation, further emphasise the enduring cost of this misuse to the person's well-being. Current service provision has failed these participants in terms of addressing the reasons for their hazardous substance regimes. This study interviewed 10 people and did not aim to generalise to the wider population with learning disabilities, but it may indicate the need for an emphasis to be placed on this population having greater access to a wider range of specialist services that can address these negative life experiences. Similarly, both intellectual disability and mainstream addiction staff need to consider utilising more recent advancements (i.e. motivational interviewing) in order to fully engage and work with this resilient population.

\section{Acknowledgements}

This research was funded by a research grant awarded by the Alcohol and Education Research Council, London, UK, to the first author (L.T.). We are grateful to all the clients and community informants who took part in this study.

\section{References}

Addictions Resource Agency for Commissioners (2002) Substance Misuse and People with Learning Disabilities . Report Commissioned by Merton Drug and Alcohol Action Team. Addictions Resource Agency for Commissioners, London.

American Psychiatric Association (1994) Diagnostic and Statistical Manual of Mental Disorders, 4th edn. American Psychiatric Association, Washington, DC.

Annand G.N. \& Rus G. (1998) Overcoming barriers to effective treatment for persons with mental retardation and substance related problems. NADD Bulletin 1 (2), 14-17.

Atkinson D. (2005) Narratives and people with learning disabilities. In: G. Grant, G. Goward, M. Richardson \& P. Ramcharan (Eds)

Learning Disability: A Life Cycle Approach to Valuing People, pp. 7-27. Open University Press, Maidenhead.

Banerjee S., Clancy C. \& Crome I. (2002) Co-existing Problems of Mental Disorders and Substance Abuse (Dual Diagnosis): An Information Manual . Royal College of Psychiatrists, London.

Barnhill J. (2000) Triple diagnosis: substance abuse disorders, mental illness and mental retardation. In: Proceedings of the NADD International Conference: New York, pp. 12-17. NADD, New York.

Barr O., McConkey R. \& McConaghie J. (2003) Views of people with learning difficulties about current and future accommodation: the use of focus groups to promote discussion. Disability Society 18, 559-577.

Burgard J.F., Donohue B., Azrin N.A. \& Teichner G. (2000) Prevalence and treatment of substance abuse in the mentally retarded population: an empirical review. Journal of Psychoactive Drugs 32 (3), 293-298.

Burnard P. (1991) A method of analysing interview transcripts in qualitative research. Nurse Education Today 11, 461-466. Campbell J.A., Essex E.L. \& Held G. (1994) Issues in chemical dependency treatment and aftercare for people with learning differences. Health Social Work 19, 63-70.

Chappell A.L. (2000) Emergence of participatory methodology in learning disability research: understanding the context. British Journal of Learning Disabilities 28(1), 38-43.

Christian L. \& Poling A. (1997) Drug abuse in persons with mental retardation: a review. American Journal on Mental Retardation 102(2), 126-136.

Clarke J.J. \& Wilson D.N. (1999) Alcohol problems and intellectual disability. Journal of Intellectual Disability Research 43, 135-139. 
Degenhardt L. (2000) Interventions for people with alcohol use disorders and an intellectual disability: a review of the literature. Journal of Intellectual and Developmental Disability 25(2), 135-146.

Department of Health (2001) Valuing People: A New Strategy for Learning Disability for the 21st Century. $\mathrm{Cm}$ 5086. The Stationery Office, London.

Emerson E. \& Turnball L. (2005) Self-reported smoking and alcohol use among adolescents with a mild intellectual disability. Journal of Intellectual Disabilities 9(1), 58-69.

Huxley A., Copello A. \& Day E. (2005) Substance misuse and the need for integrated services. Learning Disability Practice 6(8), 14-17.

Lance P. \& Longo M.D. (1997) Mental health aspects of developmental disabilities. Habilitative Mental Healthcare Newsletter 16(4), 61-64.

McConkey R., Sowney M., Milligan V. \& Barr O. (2004) Views of people with intellectual disabilities of their present and future living arrangements. Journal of Policy and Practice in Intellectual Disabilities 1(3/4), 115-125.

McGillicuddy N.B. (2006) A review of substance use research among those with mental retardation. Mental Retardation and Developmental Disabilities Research Reviews 12, 41-47.

McMurran M. \& Lismore K. (1991) Using video-tapes in alcohol interventions for people with learning disabilities. Mental Handicap 21, 29-31.

Mendel E. \& Hopkins J. (2002) Motivating learning disabled offenders with alcohol related problems: a pilot study. British Journal of Learning Disabilities 30, 153-158.

Miller W. (1983) Motivational interviewing with problem drinkers. Behaviour Psychotherapy 11, 147-172.

Miller W.R. \& Sovereign R.G. (1989) The check-up: a model for early intervention in addictive behaviours. In: T. Loberg, W. R. Miller, P. E. Nathan \& G. A. Marlatt (Eds) Addictive Behaviours: Prevention and Early Intervention, pp. 219-231. Swets \& Zeitlinger, Amsterdam.

Parahoo A.K. (2006) Nursing Research: Principles, Process and Issues. Macmillan, Basingstoke.

Prochaska J. \& DiClemente C. (1986) Toward a comprehensive model of change. In: W. Miller \& N. Heather (Eds) Treating Addictive Behaviours: Processes of Change, pp. 4-27. Plenum Press, New York, NY.

Review of Mental Health and Learning Disability (Northern Ireland) (2005) Equal Lives: Review of Policy and Services for People with a Learning Disability in Northern Ireland. Review of Mental Health and Learning Disability (Northern Ireland), Belfast.

Rivinius T. (1988) Alcohol use disorder in mentally retarded persons. Psychiatric Aspects of Mental Retardation Reviews 7, 19-26.

Robertson J., Emerson E., Gregory N., Hatton C., Turner S., Kessissoglou S. \& Hallam A. (2000) Lifestyle related risk factors for poor health in residential settings for people with intellectual disabilities. Research in Developmental Disabilities 21(6), 469-486.

Scottish Executive (2001) The Same as You? A Review of Services for People with Learning Disabilities . Scottish Executive, Edinburgh.

Slevin E. \& Sines D. (2000) Enhancing the truthfulness consistency and transferability of a qualitative study. Nurse Researcher 7(2), 79-97.

Stavrakaki C. (2002) Substance-related disorders in persons with a developmental disability. In: D. M. Griffiths, C.

Stavrakaki \& C. J. Summers (Eds) Dual Diagnosis: An Introduction to the Mental Health Needs of Persons with Developmental Disabilities, pp. 455-482. National Association for the Dually Diagnosed, Kingston, NY.

Sturmey P., Reyer H., Lee R. \& Robek A. (2003) Substance-Related Disorders in Persons with Mental Retardation. National Association for the Dually Diagnosed, Kingston, NY.

Taggart L., McLaughlin D., Quinn B. \& Milligan V. (2006) An exploration of substance misuse in people with intellectual disabilities. Journal of Intellectual Disability Research 50(8), 588-597.

Tyas S. \& Rush B. (1993) The treatment of disabled persons with alcohol and drug problems: results of a survey of addiction services. Journal on the Study of Alcohol 54, 275-282. 